\title{
Effective Actions
}

Dear Reader,

We have no alternative but to meet the targets of the Paris Agreement. Our goal must be to provide practical, affordable, and sustainable mobility solutions that will have a rapid global impact. It's the only way of protecting our climate effectively. Vehicles with combustion engines running on synthetic fuels would be a sustainable way of achieving the Paris targets and ensuring the competitiveness of the European automotive industry.

It is astounding that the political policymakers are only slowly coming to this logical conclusion. The chair of the German Green Party, Annalena Baerbock, said in December 2019 on the talk show "Anne Will”: "We have nothing against combustion engines, only against fossilfuel combustion engines." By contrast, on January 15, 2020 the chair of the German Green parliamentary group Anton Hofreiter called for a date to be set for phasing out combustion engines. The left hand obviously does not know what the right hand is doing.

The German Federal Minister for the Environment, Svenja Schulze, is heading in a different direction and wants "to develop a global strategy for the production of synthetic fuels and raw materials from green electricity (power-to-X)," as she explained on December 10, 2019 at the United Nations Climate Change Conference in Madrid. The EU's most recent resolution to put hydrogen-based mobility on an equal footing with battery electric vehicles represents an important and long overdue change of approach, even though there has been no clear commitment to the combination of combustion engines and carbon-neutral fuels as a significant contributor to global climate protection. This comes instead from the German Renewable Energy Federation whose president, Simone Peter, has said:
"In the transport sector we must give preference to alternative drive systems and renewable fuels.”

Japan and, most importantly, China have recognized that the problem is not the combustion engine, but the fossil fuel. China has not only announced that it plans to promote the development of vehicles with combustion engines, but has also stated that it will in future be using cradle-to-cradle assessments and enshrining this decision in law. As things currently stand, this will lead to electric vehicles falling into a much less favorable category than before, with foreseeable consequences for European manufacturers. Europe is just about to squander its leading role in the automotive industry in terms of both development and sales. It is high time for us to start calculating real carbon footprints and taking rapid and appropriate action.

I hope you enjoy this latest issue of ATZ.

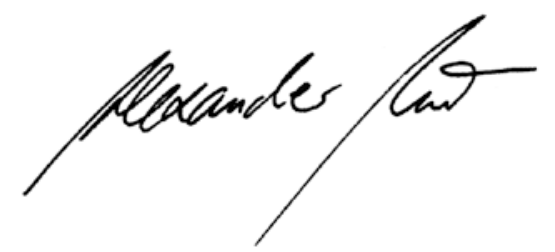

\section{Dr. Alexander Heintzel}

Editor in Chief

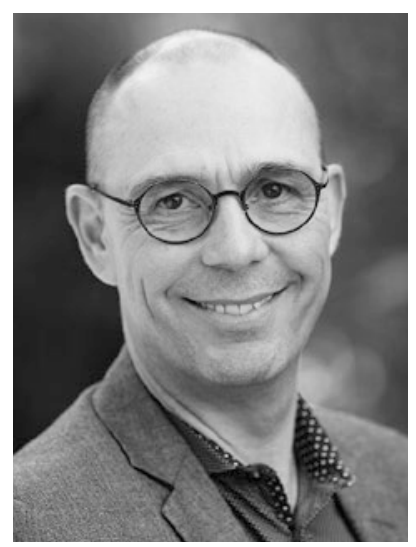

